Keywords: anal squamous intraepithelial lesions; liver transplantation; immunosuppression; anal cancer; anal cytology; high-resolution anoscopy

\title{
Liver transplant recipients have a higher prevalence of anal squamous intraepithelial lesions
}

\author{
A Albuquerque ${ }^{\star, 1,2}$, H Pessegueiro Miranda ${ }^{3,4,5}, \mathrm{~J} \mathrm{Lopes}^{6}$, J Gandara ${ }^{3,4}$, S Rodrigues ${ }^{1,2}$, R Gaspar ${ }^{1,2}$,

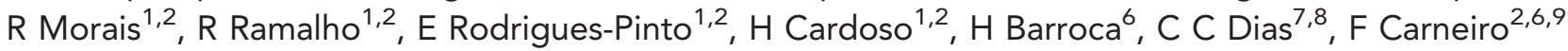 \\ and $\mathrm{G}$ Macedo ${ }^{1,2}$
}

\begin{abstract}
${ }^{1}$ Gastroenterology Department Centro Hospitalar São João, Porto, Portugal; ${ }^{2}$ Faculty of Medicine of the University of Porto, Porto, Portugal; ${ }^{3}$ Liver and Pancreatic Transplant Unit Centro Hospitalar Porto, Porto, Portugal; ${ }^{4}$ Abel Salazar BioMedical Sciences Institute from University of Porto, Porto, Portugal; ${ }^{5}$ Institute of Public Health, University of Porto, Porto, Portugal; ${ }^{6}$ Pathology Department Centro Hospitalar São João, Porto, Portugal; ${ }^{7}$ Department of Community Medicine, Information and Health Decision Sciences, Faculty of Medicine of the University of Porto, Porto, Portugal; ${ }^{8}$ Center for Health Technology and Services Research-CINTESIS, Porto, Portugal and ${ }^{9}$ Institute of Molecular Pathology and Immunology of the University of Porto (Ipatimup) and i3S - Instituto de Investigação e Inovação em Saúde, University of Porto, Porto, Portugal
\end{abstract}

Background: Anal squamous intraepithelial lesions (ASIL) are precancerous lesions of anal squamous cell carcinoma, with a higher prevalence in immunosuppressed patients. There are some studies in kidney transplant recipients, but there is no information regarding prevalence in liver transplantation. Our aim was to evaluate the prevalence of ASIL in this setting.

Methods: Prospective case-control study involving liver transplant recipients without any other known risk factor for ASIL $(n=59)$, which were compared with a healthy control group $(n=57)$. All were submitted to anal cytology and high-resolution anoscopy was performed in those with abnormal results.

Results: Ten (17\%) of liver transplant recipients had abnormal cytological results, seven patients had atypical squamous cells of undetermined significance (ASC-US), one patient had atypical squamous cells that cannot exclude high-grade (ASC-H) and two patients had high-grade squamous intraepithelial lesions (HSIL). In the control group, one patient (2\%) had an ASC-US result $(P=0.005)$. Anal squamous intraepithelial lesions were confirmed in 7 out of 10 of liver transplant patients and 0 out of 1 in the controls $(P=0.013)$ by high-resolution anoscopy with biopsies. Current smoking was the only risk factor for abnormal cytology (odds ratio $=5.87,95 \%$ confidence intervals $=1.22-28.12, P=0.027$ ).

Conclusions: Liver transplant patients have a higher risk of ASIL. Screening should be considered, especially in smokers.

Anal squamous intraepithelial lesions (ASIL) or anal intraepithelial neoplasia are precancerous lesions of anal squamous cell carcinoma (SCC) and are related to human papillomavirus (HPV) infection (Palefsky et al, 1991; Frisch et al, 1997; Varnai et al, 2006). Recently published cancer incidence and mortality projections showed that anal cancer will be one of the fastest growing cancers in terms of incidence and mortality in the United Kingdom over the next two decades (Smittenaar et al, 2016).

Cervical carcinogenesis and anal carcinogenesis have several important similarities, namely the role of $\mathrm{HPV}$, anatomic origin

*Correspondence: Dr A Albuquerque; E-mail: a.albuquerque.dias@gmail.com

Received 1 July 2017; revised 26 September 2017; accepted 29 September 2017; published online 31 October 2017

(C) 2017 Cancer Research UK. All rights reserved 0007 - 0920/17 
(squamocolumnar junction) and the same precancerous lesions (Roberts and Thurloe, 2012). In cervical screening, women are normally tested by cervical cytology and those with more suspicious results are then referred for colposcopy. If high-grade squamous intraepithelial lesions (HSIL) are confirmed, the patient is normally treated, in an effort to prevent progression to cervical cancer (Massad et al, 2013). The rationale for anal cancer screening follows the same principles as cervical cancer screening and focusses in high-risk groups (Roberts and Thurloe, 2012; Hillman et al, 2016). There are some groups that have been recognised as higher risk for ASIL and anal SCC, namely men who have sex with men (MSM), human immunodeficiency virus (HIV)-infected individuals (Machalek et al, 2012) and women with a history of lower genital tract neoplasia (Moscicki et al, 2015). Kidney transplant recipients also have a higher prevalence of ASIL (Ogunbiyi et al, 1994) and the anal cancer relative risk is 10-fold higher than in non-immunosuppressed patients (Adami et al, 2003; Patel et al, 2010). Previous studies showed a 20\% prevalence of ASIL in kidney transplant recipients and a $47 \%$ anal infection rate of HPV 16 (Ogunbiyi et al, 1994).

Although some information exists in liver transplantation concerning HPV infection, there are no studies determining the prevalence of ASIL in this population. Our aim was to evaluate the prevalence of ASIL in liver transplant recipients compared with healthy subjects.

\section{MATERIAL AND METHODS}

Study design, inclusion and exclusion criteria. This was a prospective case-control study involving liver transplant recipients that were compared with a healthy control group. Liver transplant recipients were followed at the Liver and Pancreatic Transplant Unit at Centro Hospitalar Porto and in the Gastroenterology Department of Centro Hospitalar S. João. Only liver transplant recipients older than or equal to 18 years and transplanted for $\geqslant 2$ years were included. The sex-matched healthy control group included adult patients referred to colonoscopy or that were being followed in the Gastroenterology outpatient clinic of the Gastroenterology Department of Centro Hospitalar S. João.

Patients transplanted due to familial amyloid neuropathies were not included. MSM, HIV positive, women with a history of lower genital tract neoplasia, HPV vaccination and previous history of ASIL or anal cancer patients were excluded. Patients under immunosuppressive drugs for other causes, besides liver transplantation, inflammatory bowel disease (IBD), anorectal pathology (fissure, fistula, abscess, large hemorrhoids), sexually transmitted diseases or previous cancer submitted to chemotherapy or radiotherapy, were also excluded. A history of anal receptive intercourse was considered an exclusion criteria for transplanted or control men, but not for women. No men in both groups reported practising receptive anal intercourse before study entrance. One male patient of the control group that had an abnormal cytology result confirmed, after the result was obtained, that he was a MSM. Another control subject had an anal cytology that showed the presence of cells with suspicious eosinophilic nuclear inclusions, suggesting a Herpes infection (no sign of infection was present during anal cytology collection) and he then refused further evaluation. Both patients were excluded from the final analysis (MSM and/or DST were exclusion criteria) that only included 57 controls and not the initial 59 subjects.

The study was approved by the Health Ethics Committee of Centro Hospitalar S. João (reference CES 59-16) and Centro Hospitalar Porto (reference 2016.145 124-DEFI/117-CES), and was performed in accordance with the 1964 Declaration of Helsinki and its later amendments.
Study visit and data collection. Random transplant recipients fulfiling the study criteria were enroled during a routine outpatient visit. The study was explained and the informed verbal and written consent obtained from all patients that accepted entering the study. Information on age, aetiology of liver disease, liver transplantation date, type and duration of immunosuppression, HIV infection, cancer, lower anogenital tract neoplasia or IBD diagnosis, smoking, HPV vaccination, sexual orientation, marital status, age at first sexual intercourse, number $(\leqslant$ or $>3$ ) lifetime sexual partners, history of receptive anal intercourse and last defecation time before anal cytology ( $\leqslant$ or $>1 \mathrm{~h}$ ) were recorded. After the interview, anal cytology was collected.

After full explanation of the study and the required procedures, two liver transplant recipients refused participation. None of the healthy controls refused participation.

Procedures: anal cytology and high-resolution anoscopy. All patients were submitted to anal cytology. Those with abnormal cytological results, namely HSIL, atypical squamous cells that cannot exclude high-grade squamous intraepithelial lesions (ASC$\mathrm{H}$ ), low-grade squamous intraepithelial lesions (LSIL) and atypical squamous cells of undetermined significance (ASC-US), were further evaluated with high-resolution anoscopy (HRA) and biopsies of any high-grade suspicious lesion. Only patients with a negative result for intraepithelial lesion or malignancy (NILM) were not referred.

Anal cytology was performed using a sterile polyester swab (Thermo Fisher Scientific, Waltham, MA, USA), previously moistened with water with the patients in the left lateral decubitus position. The swab was inserted in the distal rectum and then slowly withdrawn with rotating movements during 20 s. Samples were placed into PreservCyt ThinPrep solution (Hologic UK, Crawley, UK). Four experienced clinicians collected the anal cytologies: AA, SR, RG, RM; the last three were previously trained by AA.

High-resolution anoscopy was performed using a Carl Zeiss colposcope (Carl Zeiss, Oberkochen, Germany) and all procedures were performed by AA, with more than 3 years of experience and a mean number of 400 procedures per year in HRA. Patients were observed in the knee-chest position without any previous bowel preparation. A disposable anoscope was inserted and the colposcope was used to examine the squamocolumnar junction, the anal canal and the perianal skin, initially without any staining and then with the topical application of 5\% acetic acid and Lugol's iodine solution (anal application exclusively). When high-grade disease was suspected, anal and/or perianal lesions were submitted to biopsies using a mini-Tischler punch-biopsy forceps. No previous local anaesthesia was normally necessary for anal biopsies and 1\% lidocaine buffered with $8.4 \%$ of sodium bicarbonate was used for perianal biopsies.

Sample processing. All anal cytologies and biopsies were analysed in the Pathology Department of Centro Hospitalar S. João in Porto. Two cytopathologists analysed the samples blinded to the subject group and when discordant results were obtained a third opinion was recorded. Classification of cytology was done according to the Bethesda System in HSIL, ASC-H, LSIL, ASC-US and NILM. Histology was classified in LSIL and HSILs according to the Lower Anogenital Squamous Terminology (Darragh et al, 2012).

Statistic analysis. Continuous variables were described as mean \pm standard deviation or median (interquartile range) according to the distribution symmetry. Categorical variables were described as absolute and relative frequencies. The comparison between groups was made using the Student's $t$-test for parametric or the Mann-Whitney $U$-test for non-parametric continuous variable and the $\chi^{2}$-test or Fisher's exact test for categorical variables. To determine factors that were associated with cytological alterations, 
univariate and adjusted odds ratios (ORs) with a 95\% confidence intervals (CIs) were calculated using logistic regression. Two models of multivariate logistic regression were also developed using a limited number of variables due to the number of cases. One model included current smoking, age and hepatitis B and the other current smoking, age and time after transplantation. A significance level of $\alpha=5 \%$ was considered in all hypothesis tests.

For current smokers, the number of pack-years was calculated as the number of cigarettes smoked per day/20 $\times$ number of years smoked.

For the sample size calculation, an expected ASIL prevalence of $20 \%$ in the liver transplant group and $2 \%$ in controls was used, with a ratio of controls to cases $1: 1$, an $80 \%$ power and $95 \%$ confidence. Previous studies have showed an ASIL prevalence of $20 \%$ of the kidney transplant population (Ogunbiyi et al, 1994) and $0.7 \%$ to $2.6 \%$ in healthy controls (Ogunbiyi et al, 1994; Jacyntho et al, 2011). A sample of at least 57 patients in each group was deemed necessary.

Statistic analysis was performed using IBM SPSS Statistics for Windows, version 24.0 (IBM Corp., Armonk, NY, USA).

\section{RESULTS}

A total of 59 liver transplant recipients and 57 controls were included. In the liver transplant group, 37 patients (63\%) were men, with a mean age of $54 \pm 10$ years. In the healthy control group, 36 subjects $(63 \%)$ were men, with a mean age $59 \pm 11$ years. There were no statistically significant differences between groups concerning sex or smoking habits, but liver transplant recipients were younger (Table 1).

The most common aetiology for liver transplantation was alcoholic in 26 patients (44\%), hepatitis B in 7 patients (12\%), and hepatitis $\mathrm{C}$ and autoimmune hepatitis each in 6 patients (10\%). The most commonly used drug therapy was tacrolimus only $(n=23,39 \%)$ or tacrolimus and mycofenolate mofetil $(n=10$, $17 \%)$. Seven patients were also on prednisolone (12\%), associated with other drugs. Regarding immunosuppression duration, the median was 7 (5-11) years. Nine patients were current smokers (15\%), 8 in 22 women had previous anal intercourse (36\%) and 47 patients were married (80\%).

Regarding anal cytology, 10 of liver recipients (17\%) had abnormal results, 7 patients had ASC-US, 1 patient ASC-H and 2 patients HSIL. In the control group, one subject (2\%) had abnormal cytology with ASC-US $(P=0.005)$ (Table 1). All anal cytology samples were considered satisfactory for analysis and 87 out of $116(75 \%)$ were representative of the transformation zone (no statistically significant difference between the two groups).

In the univariate logistic regression, current smoking was the only risk factor for abnormal cytological results $(\mathrm{OR}=5.87,95 \%$ $\mathrm{CI}=1.22-28.12, P=0.027$ ) (Table 2). Liver transplant recipients with abnormal anal cytological results had a higher number of pack-years smoked $(P=0.012)$ with a median of $18(15-35)$ than patients with normal cytological results with a median of 10 (4$10)$. Ever smoking $(\mathrm{OR}=1.85,95 \% \mathrm{CI}=0.45-7.60, P=0.396)$ was not a risk factor for cytological abnormalities. Regarding immunosuppression, current therapy, current doses and the duration of immunosuppression (time after transplantation) were also not risk factors for abnormal results in liver transplant recipients.

Two multivariate models were developed using current smoking, as the only statistically significant factor in the univariate analysis (although current smoking was the only factor, different adjustments were done using possibly clinically significant variables). One model included current smoking, age and hepatitis $B$ and the other current smoking, age and time after
Table 1. Comparison between liver transplant patients $(n=59)$ and the control group $(n=57)$

\begin{tabular}{|c|c|c|c|}
\hline Parameter & $\begin{array}{l}\text { Control } \\
\text { group }\end{array}$ & $\begin{array}{c}\text { Liver } \\
\text { transplant }\end{array}$ & $P$-value \\
\hline Men, n (\%) & $36(63)$ & $37(63)$ & $0.960^{a}$ \\
\hline Age (years), mean \pm s.d. & $59 \pm 11$ & $54 \pm 10$ & $0.026^{b}$ \\
\hline Current smoking, $n(\%)$ & $10(18)$ & $9(15)$ & $0.739^{a}$ \\
\hline $\begin{array}{l}\text { Abnormal anal cytology, } n(\%) \\
\text { NILM, } n(\%) \\
\text { ASC-US, } n(\%) \\
\text { LSIL, } n(\%) \\
\text { ASC-H, } n(\%) \\
\text { HSIL, } n(\%)\end{array}$ & $\begin{aligned} & (2) \\
56 & (98) \\
1 & (2) \\
0 & (0) \\
0 & (0) \\
0 & (0)\end{aligned}$ & $\begin{aligned} 10 & (17) \\
49 & (83) \\
7 & (12) \\
0 & (0) \\
1 & (2) \\
2 & (3)\end{aligned}$ & $\begin{array}{c}0.005^{a} \\
-\end{array}$ \\
\hline Satisfactory cytology & $57(100)$ & $59(100)$ & - \\
\hline $\begin{array}{l}\text { Histologic abnormalities, n (\%) } \\
\text { Negative/normal, n (\%) } \\
\text { LSIL, } n(\%) \\
\text { HSIL, } n(\%)\end{array}$ & $\begin{array}{l}0(0) \\
1(100) \\
0(0) \\
0(0)\end{array}$ & $\begin{array}{l}7(12) \\
3(30) \\
5(50) \\
2(20)\end{array}$ & $\begin{array}{c}0.013^{c} \\
-\end{array}$ \\
\hline \multicolumn{4}{|c|}{ 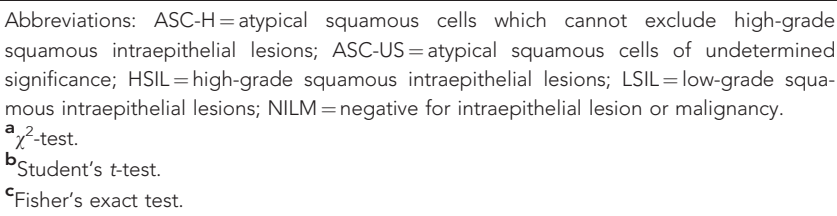 } \\
\hline
\end{tabular}

transplantation. Current smoking remained the only risk factor for cytological abnormalities (Table 3).

High-resolution anoscopy was performed in all patients with abnormal cytology results. Anal squamous intraepithelial lesions were histologically confirmed in 7 out of 10 of liver transplant patients and 0 out of 1 in the control group $(P=0.013)$. In total, five liver transplant patients had LSIL and two patients had HSIL (Table 1). Correspondence between abnormal cytology and histological results for liver transplant recipients can be seen in Table 4 .

\section{DISCUSSION}

There are no previous published data on ASIL prevalence in liver transplant recipients. Information in the transplant setting is limited to very few studies, exclusively in kidney transplant patients. Ogunbiyi et al (1994) performed a prospective case control study including 133 kidney transplant recipients and 145 controls submitted to HRA and HPV testing. Anal squamous intraepithelial lesion was present in 26 out of 133 (20\%, with $5 \%$ HSIL) of transplant recipients vs 1 out of $145(0.7 \%)$ of controls. All patients with anal HSIL, except one, had previous or concurrent lower genital tract neoplasia and these patients were not excluded from the analysis. Ogilvie et al (2008) conducted a study involving 40 kidney transplant recipients (for more than 6 months) submitted to anal cytology, HPV and HRA. No control group was used. Results showed that abnormal anal cytology was present in $2 / 35$ patients (6\%) and HRA with histology confirmed ASIL in 6 out of 39 patients (15\%) with 5\% of HSIL. Patel et al (2010) conducted a study including 108 kidney transplant patients tested with anal cytology and abnormal results were detected in 10 out of 104 (9.6\%). Results of the following anoscopy/HRA/biopsies were not provided and no control group was used. Besides the lack of publications, previous data on kidney transplantation have important limitations (inclusion of patients with other risk factors for ASIL, lack of a control group or absence of following up abnormal cytology results with HRA) that make more robust conclusions difficult to draw. This study was designed to overcome previous limitations. 
Table 2. Comparison between liver transplant patients with $(n=49)$ and without anal cytology abnormalities $(n=10)$ and univariate logistic regression analysis

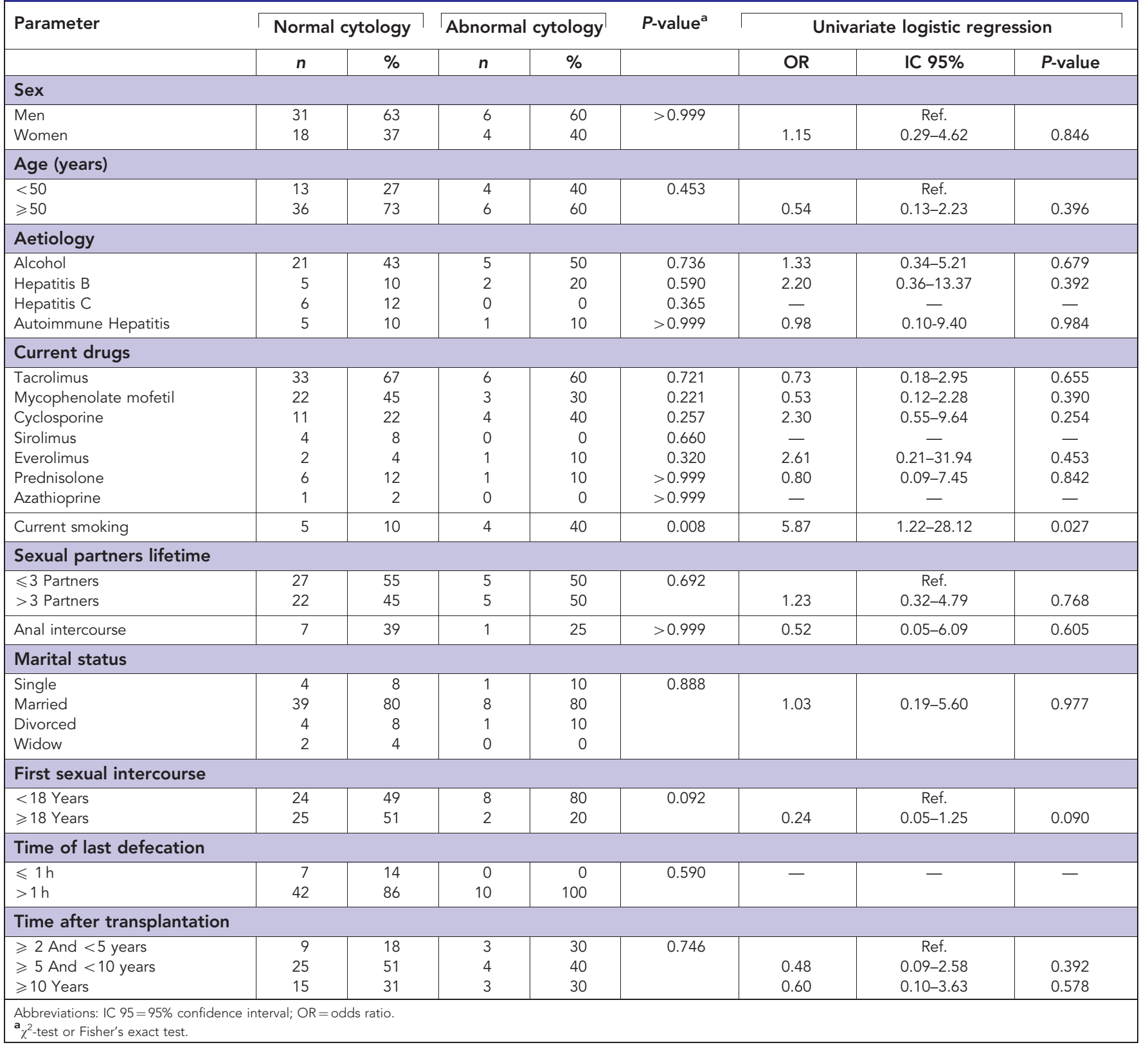

Table 3. Multivariate logistic regression analysis of cytological abnormalities

\begin{tabular}{|c|c|c|c|}
\hline & Adjusted OR & IC $95 \%$ & $P$-value \\
\hline \multicolumn{4}{|l|}{ Model 1} \\
\hline Current smoking & 5.55 & $1.07-28.72$ & 0.041 \\
\hline Hepatitis B & 1.17 & $0.16-8.81$ & 0.877 \\
\hline Age & 0.98 & $0.91-1.06$ & 0.587 \\
\hline \multicolumn{4}{|l|}{ Model 2} \\
\hline Current smoking & 7.41 & $1.34-40.98$ & 0.022 \\
\hline \multirow{5}{*}{$\begin{array}{l}\text { Time after transplantation } \\
\geqslant 2 \text { And }<5 \text { years } \\
\geqslant 5 \text { And }<10 \text { years } \\
\geqslant 10 \text { Years } \\
\text { Age }\end{array}$} & & & \\
\hline & Ref. & & \\
\hline & 0.32 & $0.05-2.11$ & 0.234 \\
\hline & 0.49 & $0.07-3.46$ & 0.474 \\
\hline & 0.99 & $0.91-1.07$ & 0.727 \\
\hline
\end{tabular}

In our analysis, a $17 \%$ prevalence of abnormal cytology was obtained in liver transplant recipients $(n=10)$, significantly higher than in controls $(P=0.005)$. Histologic confirmation of ASIL was obtained in seven patients, two with HSIL. Patients and controls that might have had other possible ASIL risks factors (other than post-transplant immunosuppression) were not included. Familial amyloid neuropathy is a common cause of liver transplantation in the Portuguese population and to select a representative and homogeneous liver transplant group, these patients were not included. Only patients with over a 2-year history of transplantation were included because of the more stable immunosuppression and the possible necessary time for anal HPV-related lesions to appear, although ASIL natural history, time and rate of progression is largely unknown. In kidney transplantation, anal lesions seem to appear $<5$ years after transplantation and increase significantly up to 10 years, when it levels out (Ogunbiyi et al, 1994), but results are conflicting (Ogilvie et al, 2008). In a previous study in HPV-related cancers after solid organ transplantation (Madeleine et al, 2013), 
Table 4. Description of the liver transplant recipients with abnormal cytology $(n=10)$

\begin{tabular}{|c|c|c|c|c|c|c|c|c|c|}
\hline Age & Sex & Aetiology & Current drugs & $\begin{array}{l}\text { Current } \\
\text { smoker }\end{array}$ & $\begin{array}{l}\text { Years of } \\
\text { transplant }\end{array}$ & Cytology & Histology & $\begin{array}{l}\text { Location of } \\
\text { lesions }\end{array}$ & $\begin{array}{l}\text { Number } \\
\text { of lesions }\end{array}$ \\
\hline 72 & Men & Alcohol & $\mathrm{MMF}+\mathrm{CYC}$ & No & 8 & ASC-US & NEGATIVE & - & - \\
\hline 56 & Men & Alcohol & TAC & No & 2 & ASC-US & NEGATIVE & - & - \\
\hline 54 & Women & PBC & $\mathrm{MMF}+\mathrm{CYC}$ & No & 3 & ASC-US & NEGATIVE & - & - \\
\hline 45 & Men & Alcohol & TAC & Yes & 4 & ASC-US & LSIL & Anal & 1 \\
\hline 51 & Men & Autoimmune hepatitis & TAC & Yes & 5 & ASC-US & LSIL & Anal & 2 \\
\hline 56 & Women & Alcohol & TAC & No & 11 & ASC-US & LSIL & Anal & 2 \\
\hline 65 & Women & Alcohol & $\mathrm{EVE}+\mathrm{CYC}$ & No & 7 & ASC-US & LSIL & Anal + perianal & 4 \\
\hline 49 & Men & Hepatitis B & CYC & Yes & 16 & ASC-H & LSIL & Anal & 1 \\
\hline 33 & Women & Wilson & $\mathrm{TAC}+\mathrm{MMF}+\mathrm{PDN}$ & No & 5 & HSIL & HSIL & Anal & 1 \\
\hline 44 & Men & Hepatitis B & TAC & Yes & 11 & HSIL & HSIL & Anal & 2 \\
\hline
\end{tabular}

the time from transplant to diagnosis of in situ (HSIL) and invasive cancers (including anal cancers) ranged from a median of 2.6-5.7 years. In addition, in this study, corticosteroids were associated with fivefold increase of in situ anal cancer (Madeleine et al, 2013). Cyclosporine and azathioprine were related to increased incidence of invasive anal cancers, and tacrolimus and mycophenolate with a decreased incidence (Madeleine et al, 2013). Although, HPVrelated precancerous lesions and cancers seem to be associated with immunosuppression and not organ related, because different organ-transplantation are associated with different immunosuppressive regimens, different rates of ASIL might be expected. Liver transplantation is the one of the most common solid-organ transplantations worldwide (second to kidney), underlining the relevance of studying this setting. Smoking was associated with ASIL in several studies (Etienney et al, 2008; Schwartz et al, 2013; Melo et al, 2014) and this was also confirmed in our analysis. A history of anal receptive intercourse is recognised as a risk factor for ASIL in men and so this was an exclusion criterion for both groups, but data are conflicting in women. A similar study in kidney transplant recipients also did not consider anal sex in women an exclusion criterion for ASIL prevalence analysis (Ogunbiyi et al, 1994).

Our results are in accordance with related published data that liver transplant recipients have a higher rate of cervical cytology abnormalities and anal HPV infection rate. A $20 \%$ prevalence of abnormal cervical cytology in early postoperative period after liver transplantation was described (Grat et al, 2017). A study by Roka et al (2004) analysed the prevalence of anal HPV infection in liver and kidney recipients before starting immunosuppressive therapy (anal cytology were obtained within $24 \mathrm{~h}$ after transplantation). HPV infection in liver patients was $29.4 \%$ (higher than in kidney transplants $29.4 \%$ vs $20.9 \%$ ) and $17.6 \%$ were high-risk HPV. In a study by Grat et al (2014), HPV prevalence was 18\% (high-risk $8 \%$ and low-risk 10\%) in the first 3 weeks after liver transplantation. Anal HPV infection was higher in patients with hepatitis B and with $\geqslant 3$ sexual partners and hepatitis $B$ infection was the only factor associated with high-risk HPV infection. No ASIL prevalence was determined by anal cytology or HRA in both of these anal HPV studies.

Solid organ transplant recipients have a higher risk of HPVrelated malignancies (Grulich et al, 2007; Madelaine et al, 2013). A study by Madelaine et al (2013) showed that solid organ transplant recipients had significantly elevated incidence of in situ and invasive HPV-related cancers at all sites (anus, penis, vagina, vulva and oropharynx), except for invasive cervical cancer. This was probably due to an effective and successful screening strategy and suggested the need for screening of other HPV-related cancers.
Anal squamous intraepithelial lesions are normally only detected with magnification and after acetic acid application they are not routinely accessible to touch (except if a cancer is already present); thus, regular digital ano-rectal examinations as the only screening method may be of limited value.

The major strengths of this study include successful HRA performance in an experienced centre in every patient with cytological abnormalities, the existence of a control group and the strict inclusion/exclusion criteria that were applied, thus ensuring that only immunosuppression in the post-transplant setting was being evaluated as a risk factor for ASIL.

Our study had some limitations and one of them is that the lack of HPV testing. This was not performed because information on HPV infection in the liver transplant patient has been previously published in two studies (Roka et al, 2004; Grat et al, 2014). Our aim was to specifically address ASIL prevalence. In the kidney transplant setting, anal HPV testing did not help to detect patients with ASIL (Ogilvie et al, 2008), but results are conflicting (Patel et al, 2010). More data, especially on the possible role of HPV genotyping in follow-up interval determination and risk stratification are required. Although the sample size for our study seems small, an initial statistical analysis found the number to be adequate. Owing to our sample size, conclusions related to the duration and type of immunosuppression impact in ASIL may be limited. There was a small difference encountered in the mean age of the groups (control group $59 \pm 11$ years $v s$ transplant $54 \pm 11$ years), probably because control subjects (slightly older) were mostly colonoscopy referrals. Anal cytology is not the ideal screening method. The sensitivity ranged from $69 \%$ to $93 \%$ and specificity from $32 \%$ to $59 \%$ in a 2006 systematic review including HIV positive individuals (Chiao et al, 2006). Although HRA is considered the 'gold standard', this technique is not routinely recommended as a screening test because it is invasive, more expensive and very few centres have trained clinicians performing it. Thus, anal cytology has been favoured as an initial screening test (Alam et al, 2016) in high-risk groups (such as transplant recipients), followed by HRA in those with abnormal results. We referred all abnormal cytological results to HRA, because even patients with cytological diagnoses of ASC-US and LSIL could be diagnosed with HSIL at HRA/biopsy. High-resolution anoscopy was not performed in every patient and this raises the possibility of having patients with normal anal cytological results (therefore not submitted to HRA) and ASIL (underestimation of the true prevalence of HSIL). The negative predictive value of anal cytology is high in comparison with HRA/histology (Jin et al, 2016) and the possibility of having false negatives and underestimation of the disease is small. 
Only patients with over 2 years of transplant were included; thus, the higher prevalence of lesions detected and the subsequent indication for screening based on this can only be extrapolated to this post-transplant period. In this study, the only focus was screening and only one sample of each of these patients was obtained. There is also a need for more data in the post-transplant setting that can complement this information, namely the performance of anal cytology and HRA in the follow-up period and the ideal follow-up intervals for this group.

HPV vaccination remains an open topic in transplantation. Vaccination ideally before transplantation should be considered. The quadrivalent HPV vaccine in the post-transplant period in adult patients seems to have suboptimal immunogenicity, especially early after transplant and in patients with a higher tacrolimus levels (Kumar et al, 2013). The rate of seropositivity only ranged from $52.6 \%$ to $68.4 \%$ depending on the HPV type (Kumar et al, 2013). The vaccine showed favourable safety and tolerability in this setting (Kumar et al, 2013). Further studies on HPV vaccination in transplanted patients are needed.

\section{CONCLUSIONS}

This study brings new and relevant information to an unexplored group and tries to overcome some of the most important limitations from previous kidney transplant studies. Recognition of high-risk groups, recommendations for screening anal precancerous lesions and prevention (like HPV vaccination) are urgently needed for improving patient care. Current anal cancer projections show that this is more relevant than ever. Liver transplant patients have a higher risk of ASIL and screening should be considered, especially in smokers.

\section{ACKNOWLEDGEMENTS}

There was no funding for this study.

\section{CONFLICT OF INTEREST}

The authors declare no conflict of interest.

\section{REFERENCES}

Adami J, Gäbel H, Lindelöf B, Ekström K, Rydh B, Glimelius B, Ekbom A, Adami HO, Granath F (2003) Cancer risk following organ transplantation: a nationwide cohort study in Sweden. Br J Cancer 89: 1221-1227.

Alam NN, White DA, Narang SK, Daniels IR, Smart NJ (2016) Systematic review of guidelines for the assessment and management of high-grade anal intraepithelial neoplasia (AIN II/III). Colorectal Dis 18: 135-146.

Chiao EY, Giordano TP, Palefsky JM, Tyring S, El Serag H (2006) Screening HIV-infected individuals for anal cancer precursor lesions: a systematic review. Clin Infect Dis 43: 223-233.

Darragh TM, Colgan TJ, Cox JT, Heller DS, Henry MR, Luff RD, McCalmont T, Nayar R, Palefsky JM, Stoler MH, Wilkinson EJ, Zaino RJ, Wilbur DC. Members of LAST Project Work Groups (2012) The Lower Anogenital Squamous Terminology Standardization Project for HPVAssociated Lesions: background and consensus recommendations from the College of American Pathologists and the American Society for Colposcopy and Cervical Pathology. J Low Genit Tract Dis 16: 205-242. Review. Erratum in: J Low Genit Tract Dis 17:368.

Etienney I, Vuong S, Daniel F, Mory B, Taouk M, Sultan S, Thomas C, Bourguignon J, de Parades V, Méary N, Balaton A, Atienza P, Bauer P (2008) Prevalence of anal cytologic abnormalities in a french referral population: a prospective study with special emphasis on HIV, HPV, and smoking. Dis Colon Rectum 51: 67-72.
Frisch M, Glimelius B, van den Brule AJ, Wohlfahrt J, Meijer CJ, Walboomers JM, Goldman S, Svensson C, Adami HO, Melbye M (1997) Sexually transmitted infection as a cause of anal cancer. N Engl J Med 337: 1350-1358.

Grạt K, Grạt M, Wronka KM, Pietrzak B, Suchońska B, Walter de Walthoffen S, Młynarczyk G, Krawczyk M, Wielgoś M (2017) Cervical human papillomavirus infection in the early postoperative period after liver transplantation: Prevalence, risk factors, and concordance with anal infections. Clin Transplant 31: e12894.

Grat M, Grat K, Hołówko W, Malejczyk M, Walter de Walthoffen S, Lewandowski Z, Kobryń K, Patkowski W, Majewski S, Młynarczyk G, Krawczyk M (2014) Initial prevalence of anal human papilloma virus infection in liver transplant recipients. Transpl Int 27: 816-823.

Grulich AE, van Leeuwen MT, Falster MO, Vajdic CM (2007) Incidence of cancers in people with HIV/AIDS compared with immunosuppressed transplant recipients: a meta-analysis. Lancet 370: 59-67.

Hillman RJ, Cuming T, Darragh T, Nathan M, Berry-Lawthorn M, Goldstone S, Law C, Palefsky J, Barroso LF, Stier EA, Bouchard C, Almada J, Jay N (2016) 2016 IANS International Guidelines for Practice Standards in the Detection of Anal Cancer Precursors. J Low Genit Tract Dis 20: 283-291.

Jacyntho CM, Giraldo PC, Horta AA, Grandelle R, Gonçalves AK, Fonseca T, Eleutério Jr J (2011) Association between genital intraepithelial lesions and anal squamous intraepithelial lesions in HIV-negative women. Am J Obstet Gynecol 205(115): e1-e5.

Jin F, Grulich AE, Poynten IM, Hillman RJ, Templeton DJ, Law CL, Farnsworth A, Garland SM, Fairley CK, Roberts JM. SPANC Study Team (2016) The performance of anal cytology as a screening test for anal HSILs in homosexual men. Cancer Cytopathol 124: 415-424.

Kumar D, Unger ER, Panicker G, Medvedev P, Wilson L, Humar A (2013) Immunogenicity of quadrivalent human papillomavirus vaccine in organ transplant recipients. Am J Transplant 13: 2411-2417.

Machalek DA, Poynten M, Jin F, Fairley CK, Farnsworth A, Garland SM, Hillman RJ, Petoumenos K, Roberts J, Tabrizi SN, Templeton DJ, Grulich AE (2012) Anal human papillomavirus infection and associated neoplastic lesions in men who have sex with men: a systematic review and meta-analysis. Lancet Oncol 13: 487-500.

Madeleine MM, Finch JL, Lynch CF, Goodman MT, Engels EA (2013) HPV-related cancers after solid organ transplantation in the United States. Am J Transplant 13: 3202-3209.

Massad LS, Einstein MH, Huh WK, Katki HA, Kinney WK, Schiffman M, Solomon D, Wentzensen N, Lawson HW. 2012 ASCCP Consensus Guidelines Conference (2013) 2012 updated consensus guidelines for the management of abnormal cervical cancer screening tests and cancer precursors. J Low Genit Tract Dis 17: S1-S27. Erratum in J Low Genit Tract Dis 17:367.

Melo VH, Guimaraes MD, Rocha GM, Araujo AC, Carmo RA, Grinsztejn B, Pilotto JH, Palefsky JM (2014) Prevalence and risk factors associated with anal intraepithelial neoplasia among HIV-positive men in Brazil. J Low Genit Tract Dis 18: 128-135.

Moscicki AB, Darragh TM, Berry-Lawhorn JM, Roberts JM, Khan MJ, Boardman LA, Chiao E, Einstein MH, Goldstone SE, Jay N, Likes WM, Stier EA, Welton ML, Wiley DJ, Palefsky JM (2015) Screening for anal cancer in women. J Low Genit Tract Dis 19: S27-S42.

Ogilvie Jr JW, Park IU, Downs LS, Anderson KE, Hansberger J, Madoff RD (2008) Anal dysplasia in kidney transplant recipients. J Am Coll Surg 207: 914-921.

Ogunbiyi OA, Scholefield JH, Raftery AT, Smith JH, Duffy S, Sharp F, Rogers K (1994) Prevalence of anal human papillomavirus infection and intraepithelial neoplasia in renal allograft recipients. Br J Surg 81: 365-367.

Palefsky JM, Holly EA, Gonzales J, Berline J, Ahn DK, Greenspan JS (1991) Detection of human papillomavirus DNA in anal intraepithelial neoplasia and anal cancer. Cancer Res 51: 1014-1019.

Patel HS, Silver AR, Levine T, Williams G, Northover JM (2010) Human papillomavirus infection and anal dysplasia in renal transplant recipients. Br J Surg 97: 1716-1721.

Roberts JM, Thurloe JK (2012) Comparison of the performance of anal cytology and cervical cytology as screening tests. Sex Health 9: 568-573.

Roka S, Rasoul-Rockenschaub S, Roka J, Kirnbauer R, Mühlbacher F, Salat A (2004) Prevalence of anal HPV infection in solid-organ transplant patients prior to immunosuppression. Transpl Int 17: 366-369. 
Schwartz LM, Castle PE, Follansbee S, Borgonovo S, Fetterman B, Tokugawa D, Lorey TS, Sahasrabuddhe VV, Luhn P, Gage JC, Darragh TM, Wentzensen N (2013) Risk factors for anal HPV infection and anal precancer in HIV-infected men who have sex with men. J Infect Dis 208: 1768-1775.

Smittenaar CR, Petersen KA, Stewart K, Moitt N (2016) Cancer incidence and mortality projections in the UK until 2035. Br J Cancer 115: 1147-1155.

Varnai AD, Bollmann M, Griefingholt H, Speich N, Schmitt C, Bollmann R, Decker D (2006) HPV in anal squamous cell carcinoma and anal intraepithelial neoplasia (AIN). Impact of HPV analysis of anal lesions on diagnosis and prognosis. Int J Colorectal Dis 21: 135-142.

This work is published under the standard license to publish agreement. After 12 months the work will become freely available and the license terms will switch to a Creative Commons AttributionNonCommercial-Share Alike 4.0 Unported License. 